\title{
The role of histone lysine demethylases in cancer cells' resistance to tyrosine kinase inhibitors
}

\author{
Jasmine Cassar White, Perla Pucci, Francesco Crea \\ School of Life Health and Chemical Sciences, The Open University, Walton Hall, Milton Keynes MK76AA, UK.
}

Correspondence to: Dr. Perla Pucci and Dr. Francesco Crea, School of Life Health and Chemical Sciences, The Open University, Walton Hall, Milton Keynes MK76AA, UK. E-mail: perla.pucci@open.ac.uk; francesco.crea@open.ac.uk

How to cite this article: White JC, Pucci P, Crea F. The role of histone lysine demethylases in cancer cells' resistance to tyrosine kinase inhibitors. Cancer Drug Resist 2019;2:326-34. http://dx.doi.org/10.20517/cdr.2019.16

Received: 22 Dec 2018 First Decision: 12 Feb 2019 Revised: 22 Feb 2019 Accepted: 4 Mar 2019 Published: 19 Jun 2019

Science Editor: Aamir Ahmad Copy Editor: Cai-Hong Wang Production Editor: Huan-Liang Wu

\begin{abstract}
Current cancer therapies are often associated with treatment failure and reduced patients' survival due to drug resistance. There are various mechanisms involved in the acquisition of cancer drug resistance, including the selection of advantageous mutations, overexpression of transporter proteins and epigenetic alterations. In this context, epigenetic alterations refer to chromatin-mediated regulation of gene expression that results in heritable changes in the cellular phenotype. There is an ever-growing body of evidence suggesting that epigenetic mechanisms play an important role in bringing about drug resistance in cancer cells. While the relationship between chemotherapy and epigenetics has been widely discussed, emerging evidence indicates that specific epigenetic effectors are also crucial for the development of resistance to tyrosine kinase inhibitors (TKIs). One particular gene that encodes the histone lysine demethylase KDM5A is overexpressed in several cancers. In breast cancer tissues, cells with KDM5A gene amplification were found to be more resistant to erlotinib, an inhibitor of the tyrosine kinase epidermal growth factor receptor (EGFR), when compared to cells without the same amplification. KDM5A was also shown to mediate resistance to a second EGFR inhibitor called gefitinib, in EGFR-mutant lung cancer cell lines. This evidence indicates that KDM5A could activate alternative survival pathways involved in overcoming EGFR inhibition. In line with these results, another histone demethylase (i.e., KDM1A) promotes liver cancer cells' resistance to the TKI sorafenib. Current evidence provides a suitable rationale to consider the use of specific KDMs inhibitors to sensitize cells to tyrosine kinase targeted therapies and thus, presents an opportunity to prevent the further development of drug resistance. This review discusses the involvement of histone lysine demethylases in the development of resistance to TKI and highlights the importance to develop new cancer treatment regimens to counteract this phenomenon.
\end{abstract}

Keywords: Epigenetics, drug resistance, cancer

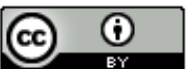

(C) The Author(s) 2019. Open Access This article is licensed under a Creative Commons Attribution 4.0 International License (https://creativecommons.org/licenses/by/4.0/), which permits unrestricted use sharing, adaptation, distribution and reproduction in any medium or format, for any purpose, even commercially, as long as you give appropriate credit to the original author(s) and the source, provide a link to the Creative Commons license, and indicate if changes were made.

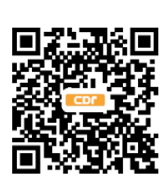




\section{INTRODUCTION}

The introduction of targeted therapies against cancer-specific molecules and signaling pathways led to significant improvements in the quality of medical care for cancer, wider therapeutic indices and more limited non-specific toxicities, when compared to earlier forms of cancer therapies ${ }^{[1]}$. Tyrosine kinases (TKs) are particularly important targets because they play a key role in the modulation of growth factor signaling, therefore influencing many downstream pathways ${ }^{[2]}$. In recent years, numerous tyrosine kinase inhibitors (TKIs) have been developed as highly effective anti-tumor and anti-leukemic agents ${ }^{[3,4]}$. Unfortunately, intrinsic TKI resistance ${ }^{[5-7]}$ and acquired therapeutic resistance ${ }^{[8-10]}$ to TKIs often develops along the course of therapy, reducing TKIs clinical efficacy and hampering effective treatment of cancer.

There are many molecular mechanisms that are involved in the acquisition of resistance to TKIs, such as mutation of drug targets, changes in drug metabolism and the over-expression of cancer drug resistance transporter proteins that result in increased rates of drug efflux ${ }^{[11]}$. Apart from this, tumors are highly adaptable to the biological microenvironment and changes in the activation and inactivation patterns of survival signaling pathways can also result in the emergence of drug resistance ${ }^{[12,13]}$. Epigenetic mechanisms have been found to play an important role in generating drug resistance in cancer cells ${ }^{[14,15]}$. In this context, epigenetic alterations refer to chromatin-mediated regulation of gene expression that results in heritable changes in the cellular phenotype ${ }^{[16]}$.

In this review we will focus on the role of a specific family of epigenetic effectors (i.e., histone lysine demethylases, KDMs) in the context of TKIs resistance.

\section{TYROSINE KINASES AND INHIBITORS: HYSIOLOGICAL FUNCTIONS AND RELEVANCE IN CANCER}

TKs are enzymes capable of selectively phosphorylating tyrosine residues in different substrates, resulting in the activation of numerous proteins involved in the signal transduction cascade ${ }^{[17]}$. Therefore TKs play key roles in mediating biological processes such as cellular differentiation, metabolism, growth and apoptosis in response to both external and internal stimuli ${ }^{[18]}$. For example, FMS Like Tyrosine Kinase 3 (FLT3) is a class III TK cytokine receptor that is expressed on the surface of immature hematopoietic progenitor cells and plays important roles in promoting the survival and correct growth of progenitor cells and hence, the control of hematopoiesis ${ }^{[19]}$. FLT3 mutations can be found in patients suffering from acute myeloid leukaemias (AMLs) and B-cell acute lymphoblastic leukaemias (ALLs) and cause uncontrolled receptor activation, constitutive FLT3 signalling and as a result, activation of the STAT4, RAS/MAPK and PI3K pathways important for cell division, apoptosis and cell formation ${ }^{[20]}$.

Due to their wide roles in many signaling pathways, the level of intra-cellular tyrosine kinase phosphorylation must be tightly controlled; this is achieved through maintenance of the balance between TKs and their antagonists, tyrosine phosphatases.

Despite being strictly regulated in physiological conditions, TKs may acquire aberrant functions caused by various mechanisms including mutations and overexpression of the $T K$ genes, leading to constitutive oncogenic TKs activation and development of malignant phenotypes ${ }^{[21]}$. There are four main mechanisms resulting in the constitutive activation of receptor TKs in human cancers: (1) gain-of-function mutations; (2) overexpression and genomic amplifications; (3) chromosomal rearrangements; and/or (4) autocrine activation $^{[17]}$.

Gain-of-function mutations in TKs lead to abnormal downstream signal transduction and can be exemplified by "driver mutations" that result in a selective growth advantage to cells. This is an important 
aspect of cancer initiation and progression ${ }^{[22]}$. Overexpression of TKs, as a result of gene amplification, in human cancers leads to an increase in the local concentration of the receptor TKs and consequent elevation of TK signaling ${ }^{[23]}$. Chromosomal rearrangements lead to the formation of new TK fusion oncoproteins, such as the BCR-ABL fusion protein ${ }^{[24]}$. Identification of such chromosomal rearrangements and the associated fusion oncoprotein can be instrumental to the development of new therapeutics as these fusion proteins are often good targets for small molecule inhibitors. Finally, autocrine activation refers to a situation where the cells are constantly secreting extra-cellular ligands that bind to receptors on the same cells, leading to the activation of specific TK pathways ${ }^{[25]}$. Autocrine activation of TKs has been identified and studied in various types of cancers, including HGF-MET in $\mathrm{AML}^{[26]}$ and SCF-KIT autocrine loop in small cell lung cancer ${ }^{[27]}$.

The effect of constitutively active TKs can be blocked through the use of TKIs, which have been found to be effective in the targeted treatment of various malignancies ${ }^{[1]}$. Imatinib was the first TKI to be developed for use against chronic myelogenous leukemia $(\mathrm{CML})^{[14]}$ and was the first TKI successfully introduced in clinical oncology ${ }^{[28]}$. Imatinib targets the BCR-ABL TK that is selectively expressed by CML cells and promotes their uncontrolled proliferation.

Since then, numerous TKIs have been discovered and developed as anti-cancer treatments targeting a vast array of cancer types. These inhibitors include gefitinib ${ }^{[29,30]}$ and erlotinib; two oral anti-cancer treatments that act as selective inhibitors of the TK domain of the EGFR. These drugs are approved for the treatment of lung cancer ${ }^{[22,23]}$ and non-small cell lung cancer and pancreatic cancer ${ }^{[31-33]}$ respectively. Ibrutinib is a first-in-class small molecule inhibitor of Bruton's tyrosine kinase (BTK) and is used to treat B cell cancers such as mantle cell lymphoma ${ }^{[34]}$ and Waldenström's macroglobulinemia ${ }^{[35]}$.

Subsequently, the activity of TKIs has been widened by designing molecules that target more than one enzyme. For example Sunitinib, an oral, small-molecule, multi-targeted receptor (PDGFR and VEGFR families) TKI was the first cancer drug to be approved for two indications, renal cell carcinoma (RCC) and imatinib-resistant gastrointestinal stromal tumour ${ }^{[36]}$, at the same time. Most recently, dasatinib, another multi-targeted TKI developed to contrast imatinib resistance ${ }^{[37]}$ and enhance TKI tolerability ${ }^{[38]}$ in patients with CP-CML, was approved for the treatment of CML and $\mathrm{ALL}^{[39,40]}$.

Cabozantinib is a newly developed small molecule inhibitor of the tyrosine kinases c-MET and VEGFR2 that is used to treat medullary thyroid cancer ${ }^{[41]}$ and a first-line treatment for advanced RCC $^{[42]}$, amongst other cancer types. Vandetanib is a small molecule TKI that targets key signaling pathways in cancer by inhibiting VEGFR-dependent tumour angiogenesis and EGFR- and RET-dependent cell proliferation and survival, and is used to treat tumours of the thyroid gland ${ }^{[43,44]}$. Trametinib is another first-in-class TKI, that acts as an allosteric inhibitor of MEK1 and MEK2 and which is approved for treatment of metastatic melanoma harboring the BRAF V600 mutation ${ }^{[45]}$.

Interestingly, the TKI ruxolitinib was the first small molecule inhibitor of JAK1/2 kinases which was used in the treatment of myelofibrosis, applied to the field of myeloproliferative neoplasms ${ }^{[46]}$ and as a result of the promising results achieved in clinical trials, approved for the treatment of myelofibrosis by the U.S. $\mathrm{FDA}^{[47,48]}$. The most recent receptor tyrosine kinase to be approved is lorlatinib, the first third-generation anaplastic lymphoma kinase (ALK) inhibitor approved for the treatment of patients with ALK-positive metastatic non-small cell lung cancer ${ }^{[49]}$.

It is important to note that while the small molecules mentioned above, are mainly used to target TKs, other types of inhibitors such as monoclonal antibodies (mAbs) can also be used to target TKs. At present, more than $70 \mathrm{mAbs}$ have been approved by the EMEA and FDA for therapeutic use ${ }^{[50]}$ and the number of 
approvals is rapidly increasing. The first two tyrosine kinases to be targeted by mAbs were the growth factor receptors EGFR and HER2. However, these treatments are currently being challenged by recently emerging therapeutics as a result of their associated side effects and the development of resistance.

\section{KDMS AND TKI RESISTANCE}

While the relationship between chemotherapy and epigenetics has been widely discussed ${ }^{[51,52]}$, emerging evidence indicates that specific epigenetic effectors are also crucial for the development of resistance to TKIs in the treatment of cancer.

Histones post-translational modifications (HPTMs) provide a mechanism for the regulation of gene expression that is transmissible from parent to offspring. The globular domain and unstructured C- or N-terminal tails of histones are subject to various covalent modifications including acetylation, phosphorylation and methylation as well as the additions of large groups such as ubiquitin and ADP-ribose ${ }^{[53]}$.

These HPTMs contribute to the control of gene expression in a context-dependent manner, by influencing the compaction of chromatin or through signaling and recruitment of other protein complexes ${ }^{[53]}$. An appropriate balance between the stability and dynamics of HPTMs is required for accurate gene expression. Carcinogenesis and tumorigenesis are highly dependent on the dysregulation of normal gene expression and thus, HPTMs such as methylation and demethylation, play a critical role in tumour progression ${ }^{[54]}$. As a result, enzymes that catalyse the PTMs (e.g., histone lysine methylases) and their removal (e.g., histone lysine demethylases) are actively being pursued as small-molecule targets for the development of new oncology therapeutics.

KDMs are a group of enzymes that catalyze the removal of mono- (me1), di- (me2) and tri-methyl (me3) marks on histones lysine residues ${ }^{[5]}$. In particular, genes encoding for various KDMs have been found to be overexpressed in several cancers ${ }^{[56-58]}$. In addition to this, some KDMs have been found to confer resistance to established TKIs [Table 1].

Over 20 KDMs enzymes have been identified thus far.

KDMs can be classified into two broad categories, depending on their catalytic mechanism of action and sequence homology: (1) lysine-specific demethylases (LSDs or KDM1 family); (2) Jumonji C-containing histone demethylases (JmjC KDMs or KDM2-8 families) ${ }^{[50]}$.

Both categories of KDMs use oxidative mechanisms to catalyze N-methyl-lysine demethylation albeit in somewhat different manners. LSDs employ Flavin adenine dinucleotide and electron transfer in their mechanism of action. As a result of this, LSDs are unable to demethylate tri-methylated lysine residues on histones since the required electron lone pair is only present on mono- and di-methylated histones ${ }^{[59]}$. The second family of JmjC KDMs uses 2-oxoglutarate and $\mathrm{O}_{2}$ as co-substrate, with $\mathrm{Fe}$ (II) employed as a cofactor for the enzymatic oxygenase reaction ${ }^{[59]}$. This means that JmjC demethylases can remove mono-, di- and tri-methyl marks on lysine residues of histones ${ }^{[59]}$.

The exact biological functions of KDMs are poorly understood. Having said this, there is significant evidence to suggest that many of these enzymes play an important role in the early stages of growth, development and differentiation of embryonic stem cells ${ }^{[60,61]}$. This is evidenced by pre-clinical experiments demonstrating that knockdown of KDM8 in mice embryos leads to protein 53 (p53) upregulation and thus, resulting in active resorption at early stages of development ${ }^{[62]}$. Strobl-Mazzulla et al ${ }^{[63]}$ also report that $\mathrm{KDM} 4 \mathrm{~A}$ is required for the expression of neural crest specifier genes in embryonic chicken since knockdown of KDM4A in these cells leads to a significant decrease in the expression of the said genes. 
Table 1. KDMs and their links to human cancers tyrosine kinase inhibitor treatment resistance

\begin{tabular}{|c|c|c|c|c|}
\hline Enzyme & Cancer & TKI & Ref. & KDM inhibitors in clinical trials \\
\hline \multirow[t]{2}{*}{ KDM1A } & Non-small cell lung cancer & Gefitinib & {$[67]$} & \multirow{2}{*}{$\begin{array}{l}\text { 4SC-202 } \\
\text { ORY-1081 } \\
\text { Tranylcypromine } \\
\text { T69,71] }\end{array}$} \\
\hline & Hepatocellular carcinoma & Sorafenib & {$[72]$} & \\
\hline \multirow[t]{2}{*}{ KDM5A } & Breast cancer & Erlotinib & [73] & \\
\hline & Lung cancer & Gefitinib & [74] & \\
\hline KDM5B & Non-small cell lung cancer & Gefitinib & [67] & \\
\hline KDM5C & Lewis lung carcinoma, renal cell carcinoma & Sunitinib & {$[75]$} & \\
\hline KDM6A & TEL-ABL-positive acute lymphoblastic leukaemia & Imatinib & {$[76]$} & \\
\hline
\end{tabular}

TKI: tyrosine kinase inhibitor

Apart from being involved in the early stages of embryonic development and differentiation, KDMs have been shown to exhibit dysregulated expression patterns in many cancer types ${ }^{[60]}$. This can have a myriad of effects on the cell functions, including transcriptional activation of tumour oncogenes, transcriptional repression of tumour suppressors, disruption of chromosomal stability as well as interaction with key hormonal receptors that control cellular proliferation ${ }^{[64-66]}$. The role of KDMs in mediating these pathways can also have implications in cancer TKI resistance. Table 1 summarizes the alterations of various KDMs and their links to TKI cancer treatment resistance.

Recently, some KDMs such as KDM1A and KDM5A, have been found to be critical epigenetic factors for the development of resistance to TKIs such as erlotinib ${ }^{[73]}$, sorafenib ${ }^{[72]}$ and gefitinib ${ }^{[67,74]}$. The relationship between KDMs and this resistance in various tumours is emerging from recent studies and seems to be a promising field to pave the way for future potential clinical applications ${ }^{[67,72-76]}$. Hence, there is a growing body of evidence documenting this interaction and the various roles played by KDMs in mediating TKI resistance ${ }^{[6,72-76]}$.

Hou et al. ${ }^{[73]}$ investigated the role played by KDM5A in breast cancer. The authors reported that breast cancer cells with KDM5A gene amplification and hence, with up-regulated KDM5A mRNA and protein levels, were found to be more tolerant to the EGF receptor TKI erlotinib when compared to cells without the same amplification ${ }^{[62]}$. Knockdown of KDM5A in these cells led to a significant reduction in the population of drugtolerant cells ${ }^{[62]}$. Of note, KDM5A was found to exhibit an inverse expression relationship with BAK1 (BCL2antagonist/killer 1), a protein that acts as a pro-apoptotic regulator. Hou et al. ${ }^{[73]}$ reported that deletion of $K D M 5 A$ in a population of breast cancer cells with amplified KDM5A, resulted in up-regulation of $B A K 1$, suggesting that KDM5A regulates the expression of this gene, amongst others.

In addition to this, KDM5A was also shown to mediate resistance to a second EGFR inhibitor, called gefitinib, in EGFR-mutant lung cancer cell lines ${ }^{[77]}$. In order to investigate whether KDM5A was actively involved in this phenotype, Gale et al. ${ }^{[74]}$ performed colony formation assays. Through these assays, the authors were able to show that fewer cells treated with a KDM5A inhibitor YUKA1, formed colonies during long-term treatment with gefitinib when compared to a population of control cells treated with DMSO (vehicle) and the same gefitinib long-term treatment ${ }^{[74]}$. Thus, the authors provided the first evidence that the demethylase activity of KDM5A is involved in gefitinib resistance in lung cancer cells ${ }^{[7]}$.

Two other KDMs, KDM1A and KDM5B were also found to play key roles in the development of hypoxiainduced resistance to gefitinib in patients with non-small cell lung cancer (NSCLC) ${ }^{[67]}$, albeit through a different mechanism than the one reported by Gale et al. ${ }^{[74]}$. Lu et al. ${ }^{[67]}$ were able to show that knockdown of KDM1 A and KDM5B, prevented hypoxia-induced gefitinib resistance and also, inhibited epithelialmesenchymal transition (EMT) that is critical for metastasis and drug resistance ${ }^{[67,78]}$. The results suggested that hypoxia is critical for the acquisition of resistance to EGFR TKIs, as a result of epigenetic change and mediation of EMT in NSCLC ${ }^{[67]}$. 
In line with these results, KDM1A, was found to promote liver cancer cells' resistance also to the TKI sorafenib $^{[72]}$. In their publication, the authors reported an increased expression of KDM1A in sorafenibresistance hepatocellular carcinoma cells. Furthermore, the inhibition of KDM1A using two potent KDM1A inhibitors, GSK2879552 $2^{[79]}$ and pargyline ${ }^{[80,81]}$ was found to re-sensitize the same cells to the effect of sorafenib, partly through suppression of the Wnt/b-catenin signalling pathway and through reduction of the population of cancer stem cell-like cells ${ }^{[72]}$. Signalling mediated by the Wnt family of glycoproteins is one of the most important mechanisms that direct cell proliferation, polarity and determine cell fate during embryonic development and tissue homeostasis ${ }^{[82]}$. As a result of this, alterations in the Wnt pathway are often linked to cancer, amongst other diseases.

Other KDMs have also been implicated in the development of TKIs resistance, although their roles in this context need to be furtherly investigated. $\mathrm{KDM}_{5} \mathrm{C}$ was found to be a critical epigenetic modulator in the development of resistance to sunitinib in two different cancer cell lines of Lewis lung carcinoma and $\mathrm{RCC}^{[75]}$. Zimmermannova et al. ${ }^{[76]}$ have also reported the aberration of the KDM6A gene in imatinibresistant cell lines of TEL-ABL-positive acute lymphoblastic leukaemia. In contrast with this finding, the aberration of this gene did not result in the expression of aberrant KDM6A protein ${ }^{[76]}$, so further research is required to fully determine the involvement of this demethylase in the development of TKI resistance in this cancer type.

Taken together this experimental evidence indicates that KDMs play key roles in the development of resistance to TKIs in several cancer types. Recent evidence also provides a suitable rationale to consider the use of new therapies that can be used to combat this phenomenon and prevent further development of cancer drug resistance. One approach could be to consider the use of specific KDM inhibitors to resensitize cells to tyrosine kinase target therapies. The data presented in this article also suggest that combination therapies that make use of TKIs and KDM inhibitors could possibly prevent, or reverse, the acquisition of resistance through epigenetic modulations and thus, could offer an attractive therapeutic strategy for certain cancers. In this context, it will be important to employ genetic and epigenetic stratification techniques to select patients that are more likely to benefit from the combination between TKIs and KDM inhibitors.

\section{CONCLUSION}

To conclude, targeting KDMs is currently an active area of research in the development of new epigenetic drugs. Taking into account that many KDMs have been found to be amplified or overexpressed in a wide variety of human cancers and have been shown to play critical roles in mediating TKI resistance, these enzymes could be considered to be very attractive targets for the development of new therapeutic combinations.

\section{DECLARATIONS}

\section{Authors' contributions}

Made substantial contributions to conception and design: White JC, Pucci P, Crea F

Made substantial contribution in drafting the article and acquisition of the main literature: White JC

Contributed to the writing of the manuscript and critical revising: Pucci P, Crea F

Made substantial contribution in the revision process: White JC, Pucci $\mathrm{P}$

Gave final approval of the submitted version and revised version to be submitted: Crea $F$

\section{Availability of data and materials}

Not applicable. 


\section{Financial support and sponsorship}

None.

\section{Conflicts of interest}

All authors declared that there are no conflicts of interest.

\section{Ethical approval and consent to participate}

Not applicable.

\section{Consent for publication}

Not applicable.

\section{Copyright}

(C) The Author(s) 2019

\section{REFERENCES}

1. Arora A, Scholar EM. Role of tyrosine kinase inhibitors in cancer therapy. J Pharmacol Exp Ther 2005;315:971-9.

2. Hollenberg MD. Tyrosine kinase-mediated signal transduction pathways and the actions of polypeptide growth factors and G-proteincoupled agonists in smooth muscle. Mol Cell Biochem 1995;149-150:77-85.

3. Anafi M, Gazit A, Zehavi A, Ben-Neriah Y, Levitzki A. Tyrphostin-induced inhibition of p210bcr-abl tyrosine kinase activity induces K562 to differentiate. Blood 1993;82:3524-9.

4. Meydan N, Grunberger T, Dadi H, Shahar M, Arpaia E, et al. Inhibition of acute lymphoblastic leukaemia by a Jak-2 inhibitor. Nature 1996;379:645-8.

5. Oxnard GR, Lo PC, Nishino M, Dahlberg SE, Lindeman NI, et al. Natural history and molecular characteristics of lung cancers harboring EGFR exon 20 insertions. J Thorac Oncol 2013;8:179-84.

6. Arcila ME, Nafa K, Chaft JE, Rekhtman N, Lau C, et al. EGFR exon 20 insertion mutations in lung adenocarcinomas: prevalence, molecular heterogeneity, and clinicopathologic characteristics. Mol Cancer Ther 2013;12:220-9.

7. Yang JC, Sequist LV, Geater SL, Tsai CM, Mok TS, et al. Clinical activity of afatinib in patients with advanced non-small-cell lung cancer harbouring uncommon EGFR mutations: a combined post-hoc analysis of LUX-Lung 2, LUX-Lung 3, and LUX-Lung 6. Lancet Oncol 2015;16:830-8

8. Sequist LV, Waltman BA, Dias-Santagata D, Digumarthy S, Turke AB, et al. Genotypic and histological evolution of lung cancers acquiring resistance to EGFR inhibitors. Sci Transl Med 2011;3:75ra26.

9. Campo M, Gerber D, Gainor JF, Heist RS, Temel JS, et al. Acquired resistance to first-line afatinib and the challenges of prearranged progression biopsies. J Thorac Oncol 2016;11:2022-6.

10. Yu HA, Arcila ME, Rekhtman N, Sima CS, Zakowski MF, et al. Analysis of tumor specimens at the time of acquired resistance to EGFR-TKI therapy in 155 patients with EGFR-mutant lung cancers. Clin Cancer Res 2013;19:2240-7.

11. Holohan C, Van Schaeybroeck S, Longley DB, Johnston PG. Cancer drug resistance: an evolving paradigm. Nat Rev Cancer 2013;13:714-26

12. Debatin KM, Krammer PH. Death receptors in chemotherapy and cancer. Oncogene 2004;23:2950-66.

13. Lowe SW, Cepero E, Evan G. Intrinsic tumour suppression. Nature 2004;432:307-15.

14. Druker BJ, Tamura S, Buchdunger E, Ohno S, Segal GM, et al. Effects of a selective inhibitor of the Abl tyrosine kinase on the growth of Bcr-Abl positive cells. Nat Med 1996;2:561-6.

15. Taylor ST, Hickman JA, Dive C. Epigenetic determinants of resistance to etoposide regulation of Bcl-X(L) and bax by tumor microenvironmental factors. J Natl Cancer Inst 2000;92:18-23.

16. Goldberg AD, Allis CD, Bernstein E. Epigenetics: a landscape takes dhape. Cell 2007;128:635-8.

17. Lemmon MA, Schlessinger J. Cell signaling by receptor tyrosine kinases. Cell 2010;141:1117-34.

18. Paul MK, Mukhopadhyay AK. Tyrosine kinase - role and significance in cancer. Int J Med Sci 2004;1:101-15.

19. Lisovsky M, Estrov Z, Zhang X, Consoli U, Sanchez-Williams G, et al. Flt3 ligand stimulates proliferation and inhibits apoptosis of acute myeloid leukemia cells: regulation of Bcl-2 and Bax. Blood 1996;88:3987-97.

20. Testa U, Pelosi E. The impact of FLT3 mutations on the development of acute myeloid leukemias. Leuk Res Treatment 2013;2013:275760.

21. Bertram JS. The molecular biology of cancer. Mol Aspects Med 2000;21:167-223.

22. Vogelstein B, Papadopoulos N, Velculescu VE, Zhou S, Diaz LA Jr, et al. Cancer genome landscapes. Science 2013;339:1546-58.

23. Carraway KL, Sweeney C. EGF receptor activation by heterologous mechanisms. Cancer Cell 2002;1:405-6.

24. Groffen J, Stephenson JR, Heisterkamp N, de Klein A, Bartram CR, et al. Philadelphia chromosomal breakpoints are clustered within a limited region, bcr, on chromosome 22. Cell 1984;36:93-9.

25. Singh AB, Harris RC. Autocrine, paracrine and juxtacrine signaling by EGFR ligands. Cell Signal 2005;17:1183-93. 
26. Kentsis A, Reed C, Rice KL, Sanda T, Rodig SJ, et al. Autocrine activation of the MET receptor tyrosine kinase in acute myeloid leukemia. Nat Med 2012;18:1118-22.

27. Krystal GW, Hines SJ, Organ CP. Autocrine growth of small cell lung cancer mediated by coexpression of c-kit and stem cell factor. Cancer Res 1996;56:370-6.

28. O'Brien SG, Guilhot F, Larson RA, Gathmann I, Baccarani M, et al. Imatinib compared with interferon and low-dose cytarabine for newly diagnosed chronic-phase chronic myeloid leukemia. N Engl J Med 2003;348:994-1004.

29. Kris MG, Natale RB, Herbst RS, Lynch T, Prager D, et al. A phase II trial of ZD1839 (Iressa) in advanced non-small cell lung cancer (NSCLC) patients who had failed platinum- and docetaxel-based regimens (IDEAL 2). Proc Am Soc Clin Oncol 2002;21.

30. Fukuoka M, Yano S, Giaccone G, Tamura T, Nakagawa K, et al. Multi-institutional randomized phase II trial of gefitinib for previously treated patients with advanced non-small-cell lung cancer. J Clin Oncol 2003;21:2237-46.

31. Hidalgo M, Siu LL, Nemunaitis J, Rizzo J, Hammond LA, et al. Phase I and pharmacologic study of OSI-774, an epidermal growth factor receptor tyrosine kinase inhibitor, in patients with advanced solid malignancies. J Clin Oncol 2001;19:3267-79.

32. Moore MJ, da Cunha Santos G, Kamel-Reid S, Chin K, Tu D, et al. The relationship of K-ras mutations and EGFR gene copy number to outcome in patients treated with Erlotinib on national cancer institute of canada clinical trials group trial study PA.3. J Clin Oncol 2007;25:4521.

33. Moore MJ, Goldstein D, Hamm J, Figer A, Hecht JR, et al. Erlotinib plus gemcitabine compared with gemcitabine alone in patients with advanced pancreatic cancer: a phase III trial of the national cancer institute of canada clinical trials group. J Clin Oncol 2007;25:1960-6.

34. de Claro RA, McGinn KM, Verdun N, Lee SL, Chiu HJ, et al. CCR perspectives in drug approval FDA approval: ibrutinib for patients with previously treated mantle cell lymphoma and previously treated chronic lymphocytic leukemia CME staff planners' disclosures acknowledgment of financial or other support. Clin Cancer Res 2015;21:3586-90.

35. Castillo JJ, Palomba ML, Advani R, Treon SP. Ibrutinib in waldenström macroglobulinemia: latest evidence and clinical experience. Ther Adv Hematol 2016;7:179-86.

36. Sun L, Liang C, Shirazian S, Zhou Y, Miller T, et al. Discovery of 5-[5-Fluoro-2-oxo-1,2-dihydroindol-(3Z)-ylidenemethyl]-2,4dimethyl-1H-pyrrole-3-carboxylic acid (2-diethylaminoethyl)amide, a novel tyrosine kinase inhibitor targeting vascular endothelial and platelet-derived growth factor receptor tyrosine kinase. J Med Chem 2003;46:1116-9.

37. Shah NP, Sawyers CL. Mechanisms of resistance to STI571 in philadelphia chromosome-associated leukemias. Oncogene 2003;22:7389-95.

38. Druker BJ, Guilhot F, O’Brien SG, Gathmann I, Kantarjian H, et al. Five-year follow-up of patients receiving imatinib for chronic myeloid leukemia. N Engl J Med 2006;355:2408-17.

39. Shah NP, Tran C, Lee FY, Chen P, Norris D, et al. Overriding imatinib resistance with a novel ABL kinase inhibitor. Science 2004;305:399-401.

40. Lombardo LJ, Lee FY, Chen P, Norris D, Barrish JC, et al. Discovery of N-(2-chloro-6-methyl-phenyl)-2-(6-(4-(2-hydroxyethyl)piperazin-1-yl)-2-methylpyrimidin-4-ylamino)thiazole-5-carboxamide (BMS-354825), a dual src/abl kinase inhibitor with potent antitumor activity in preclinical assays. J Med Chem 2004;47:6658-61.

41. Grüllich C. Cabozantinib: a met, ret, and VEGFR2 tyrosine kinase inhibitor. Recent Results Cancer Res 2014;201:207-14.

42. U.S. Food and Drug Administration. FDA grants regular approval to cabometyx for first-line treatment of advanced renal cell carcinoma. Available from: https://www.fda.gov/Drugs/InformationOnDrugs/ApprovedDrugs/ucm589842. [Last assessed on 27 Mar 2019]

43. Zhou Y, Zhang Y, Zou H, Cai N, Chen X, et al. The multi-targeted tyrosine kinase inhibitor vandetanib plays a bifunctional role in nonsmall cell lung cancer cells. Sci Rep 2015;5:8629.

44. Morabito A, Piccirillo MC, Falasconi F, De Feo G, Del Giudice A, et al. Vandetanib (ZD6474), a dual inhibitor of vascular endothelial growth factor receptor (VEGFR) and epidermal growth factor receptor (EGFR) tyrosine kinases: current status and future directions. Oncologist 2009;14:378-90.

45. Lugowska I, Koseła-Paterczyk H, Kozak K, Rutkowski P. Trametinib: a MEK inhibitor for management of metastatic melanoma. Onco Targets Ther 2015;8:2251-9.

46. Verstovsek S, Kantarjian H, Mesa RA, Pardanani AD, Cortes-Franco J, et al. Safety and efficacy of INCB018424, a JAK1 and JAK2 inhibitor, in myelofibrosis. N Engl J Med 2010;363:1117-27.

47. Verstovsek S, Mesa RA, Gotlib J, Levy RS, Gupta V, et al. A double-blind, placebo-controlled trial of ruxolitinib for myelofibrosis. N Engl J Med 2012;366:799-807.

48. Harrison C, Kiladjian JJ, Al-Ali HK, Gisslinger H, Waltzman R, et al. JAK inhibition with ruxolitinib versus best available therapy for myelofibrosis. N Engl J Med 2012;366:787-98.

49. Johnson TW, Richardson PF, Bailey S, Brooun A, Burke BJ, et al. Discovery of (10R)-7-Amino-12-fluoro-2,10,16-trimethyl-15-oxo10,15,16,17-tetrahydro-2H-8,4-(metheno)pyrazolo[4,3-h][2,5,11]-benzoxadiazacyclotetradecine-3-carbonitrile (PF-06463922), a Macrocyclic Inhibitor of Anaplastic Lymphoma Kinase (ALK) and c-ros oncogene 1 (ROS1) with preclinical brain exposure and boardspectrum potency against ALK-resistant mutations. J Med Chem 2014;57:4720-44.

50. Animal Cell Technology Industrial Platform. Monoclonal antibodies approved by the EMA and FDA for therapeutic use (status 2017). Available from: http://www.actip.org/products/monoclonal-antibodies-approved-by-the-ema-and-fda-for-therapeutic-use. [Last assessed on 27 Mar 2019]

51. Liu MZ, McLeod HL, He FZ, Chen XP, Zhou HH, et al. Epigenetic perspectives on cancer chemotherapy response. Pharmacogenomics 2014;15:699-715.

52. Strauss J, Figg WD. Using epigenetic therapy to overcome chemotherapy resistance. Anticancer Res 2016;36:1-4.

53. Bannister AJ, Kouzarides T. Regulation of chromatin by histone modifications. Cell Res 2011;21:381-95. 
54. Kharkar VJ, Ast A, Gupta S, Sharma S. LSD2/KDM1B/AOF1 and human cancer pathways: a literature review. Cancer Stud Ther 2016;1:1-5.

55. Greer EL, Shi Y. Histone methylation: a dynamic mark in health, disease and inheritance. Nat Rev Genet 2012;13:343-57.

56. Suzuki T, Terashima M, Tange S, Ishimura A. Roles of histone methyl-modifying enzymes in development and progression of cancer. Cancer Sci 2013;104:795-800.

57. Rotili D, Mai A. Targeting histone demethylases: a new avenue for the fight against cancer. Genes Cancer 2011;2:663-79.

58. Tian X, Zhang S, Liu HM, Zhang YB, Blair CA, et al. Histone lysine-specific methyltransferases and demethylases in carcinogenesis: new targets for cancer therapy and prevention. Curr Cancer Drug Targets 2013;10:558-79.

59. Thinnes CC, England KS, Kawamura A, Chowdhury R, Schofield CJ, et al. Targeting histone lysine demethylases - progress, challenges, and the future. Biochim Biophys Acta 2014;1839:1416-32.

60. Fu X, Zhang P, Yu B. Advances toward LSD1 inhibitors for cancer therapy. Future Med Chem 2017;9:1227-42.

61. Kang MK, Mehrazarin S, Park NH, Wang CY. Epigenetic gene regulation by histone demethylases: emerging role in oncogenesis and inflammation. Oral Dis 2017;23:709-20.

62. Oh S, Janknecht R. Histone demethylase JMJD5 is essential for embryonic development. Biochem Biophys Res Commun 2012;420:615 .

63. Strobl-Mazzulla PH, Sauka-Spengler T, Bronner-Fraser M. Histone demethylase JmjD2A regulates neural crest specification. Dev Celll 2010;19:460-8.

64. Black JC, Manning AL, Van Rechem C, Kim J, Ladd B, et al. KDM4A lysine demethylase induces site-specific copy gain and rereplication of regions amplified in tumors. Cell 2013;154:541-55.

65. Young LC, Hendzel MJ. The oncogenic potential of Jumonji D2 (JMJD2/KDM4) histone demethylase overexpression. Biochem Cell Biol 2013;91:369-77.

66. Young LC, McDonald DW, Hendzel MJ. Kdm4b histone demethylase is a DNA damage response protein and confers a survival advantage following $\gamma$-Irradiation. J Biol Chem 2013;288:21376-88.

67. Lu Y, Liu Y, Oeck S, Glazer PM. Hypoxia promotes resistance to EGFR inhibition in NSCLC cells via the histone demethylases, LSD1 and PLU-1. Mol Cancer Res 2018;16:1458-69.

68. Oral histone deacetylase inhibitor 4SC-202 in patients with advanced hematologic malignancies (TOPAS). Available from: https:// clinicaltrials.gov/ct2/show/NCT01344707. [Last assessed on 27 Mar 2019]

69. European Medicines Agency. Clinical trials register - search for ORY-1001. Available from: https://www.clinicaltrialsregister.eu/ctrsearch/search?query=ORY-1001. [Last assessed on 27 Mar 2019]

70. U.S. National Library of Medicine. Study of sensitization of Non-M3 AML blasts to ATRA by epigenetic treatment with tranylcypromine (TCP) (TRANSATRA). Available from: https://clinicaltrials.gov/ct2/show/NCT02717884. [Last assessed on $27 \mathrm{Mar}$ 2019]

71. U.S. National Library of Medicine. Phase 1 study of TCP-ATRA for adult patients with AML and MDS (TCP-ATRA). Available from: https://clinicaltrials.gov/ct2/show/NCT02273102. [Last assessed on 27 Mar 2019]

72. Huang M, Chen C, Geng J, Han D, Wang T, et al. Targeting KDM1A attenuates Wnt/ $\beta$-catenin signaling pathway to eliminate sorafenibresistant stem-like cells in hepatocellular carcinoma. Cancer Lett 2017;398:12-21.

73. Hou J, Wu J, Dombkowski A, Zhang K, Holowatyj A, et al. Genomic amplification and a role in drug-resistance for the KDM5A histone demethylase in breast cancer. Am J Transl Res 2012;4:247-56.

74. Gale M, Sayegh J, Cao J, Norcia M, Gareiss P, et al. Screen-identified selective inhibitor of lysine demethylase 5A blocks cancer cell growth and drug resistance. Oncotarget 2016;7:39931-44.

75. Fahim Golestaneh A, Sun M, Schwager C, Tang Z, Macher-Goeppinger S, et al. Abstract 3254: discovery of histone demethylase KDM5C inactivation as a novel mechanism for tumors resistant to VEGF RTKi via genome-wide in-vivo RNAi. Cancer Res 2016;76:3254.

76. Zimmermannova O, Kanderova V, Kuzilkova D, Lund-Johansen F, Doktorova E, et al. Multilevel molecular profiling to dissect resistance to tyrosine kinase inhibitors in TEL/ABL positive acute lymphoblastic leukemia. Available from: https://www.linkos.cz/lekara-multidisciplinarni-tym/kongresy/po-kongresu/databaze-tuzemskych-onkologickych-konferencnich-abstrakt/multilevel-molecularprofiling-to-dissect-resistance-to-tyrosine-kinase-inhibito/. [Last assessed on 27 Mar 2019]

77. Sharma SV, Lee DY, Li B, Quinlan MP, Takahashi F, et al. A chromatin-mediated reversible drug-tolerant state in cancer cell subpopulations. Cell 2010;141:69-80.

78. Shibue T, Weinberg RA. EMT, CSCs, and drug resistance: the mechanistic link and clinical implications. Nat Rev Clin Oncol 2017;14:611-29.

79. Mohammad HP, Smitheman KN, Kamat CD, Soong D, Federowicz KE, et al. A DNA hypomethylation signature predicts antitumor activity of LSD1 inhibitors in SCLC. Cancer Cell 2015;28:57-69.

80. Liang Y, Vogel JL, Narayanan A, Peng H, Kristie TM. Inhibition of the histone demethylase LSD1 blocks $\alpha$-herpesvirus lytic replication and reactivation from latency. Nat Med 2009;15:1312-7.

81. Fiskus W, Sharma S, Shah B, Portier BP, Devaraj SGT, et al. Highly effective combination of LSD1 (KDM1A) antagonist and panhistone deacetylase inhibitor against human AML cells. Leukemia 2014;28:2155-64.

82. Kusserow A, Pang K, Sturm C, Hrouda M, Lentfer J, et al. Unexpected complexity of the Wnt gene family in a sea anemone. Nature 2005;433:156-60. 